Article

\title{
Aqueous Two-Phase System-Ion Chromatography for Determination of Thiocyanate in Raw Milk
}

\author{
Bin Jiang ${ }^{1} \mathbb{1}$, Shaojing Zhong ${ }^{1}$, Hongliang Yu ${ }^{1}$, Peifeng Chen ${ }^{1}$, Baoyun Li ${ }^{1}$, Dongmei Li ${ }^{1}$, Chunhong Liu ${ }^{1} \mathbb{D}$, \\ Zhibiao Feng ${ }^{1, *}$ and Bo Tian ${ }^{2, *}$
}

1 Department of Chemistry, College of Arts and Sciences, Northeast Agricultural University, Harbin 150030, China; jiangbin@neau.edu.cn (B.J.); m17853510711@163.com (S.Z.); yuhongliang97@163.com (H.Y.); chenpeifeng20@163.com (P.C.); libaoyun129@163.com (B.L.); lidongmei@neau.edu.cn (D.L.); liuchunhong@neau.edu.cn (C.L.)

2 College of Food Science, Northeast Agricultural University, Harbin 150030, China

* Correspondence: fengzhibiao@neau.edu.cn (Z.F.); tianbot@163.com (B.T.)

Citation: Jiang, B.; Zhong, S.; Yu, H.; Chen, P.; Li, B.; Li, D.; Liu, C.; Feng,

Z.; Tian, B. Aqueous Two-Phase System-Ion Chromatography for Determination of Thiocyanate in Raw Milk. Separations 2021, 8, 212. https://doi.org/10.3390/separations 8110212

Academic Editor: Gavino Sanna

Received: 18 September 2021

Accepted: 8 November 2021

Published: 9 November 2021

Publisher's Note: MDPI stays neutral with regard to jurisdictional claims in published maps and institutional affiliations.

Copyright: (C) 2021 by the authors Licensee MDPI, Basel, Switzerland. This article is an open access article distributed under the terms and conditions of the Creative Commons Attribution (CC BY) license (https:/ / creativecommons.org/licenses/by/ $4.0 /)$.

\begin{abstract}
Thiocyanate could effectively inhibit bacteria in milk and extend the shelf life of milk. However, excessive addition will lead to health risks. Therefore, the determination of thiocyanate in raw milk has received a lot of attention, but the determination could be interfered with by other components in raw milk and the pre-treatment of raw milk is complex. In this study, a new pretreatment method combined with ion chromatography (IC) for rapid and sensitive determination of thiocyanate is proposed. An acetonitrile/ $\left(\mathrm{NH}_{4}\right)_{2} \mathrm{SO}_{4}$ aqueous two-phase system (ATPS) was developed for the separation and enrichment of thiocyanate in raw milk. Response surface methodology was performed to optimize the extraction conditions and an efficient pretreatment were obtained using ATPS composed of $42 \%$ acetonitrile $(w / w)$ and $16 \%\left(\mathrm{NH}_{4}\right)_{2} \mathrm{SO}_{4}(w / w)$, with the $\mathrm{pH} 4.7$, and the recovery of thiocyanate reached $107.24 \pm 0.5 \%$, and the enrichment ratio was $10.74 \pm 0.03$. IC was used to establish a thiocyanate enrichment method. The linear range was from 0.05 to $15 \mathrm{mg} / \mathrm{L}$ and $\mathrm{R}^{2}=0.998$, the limit of detection (LOD) was $0.2 \mu \mathrm{g} / \mathrm{L}$, the limit of quantification (LQD) was $0.6 \mu \mathrm{g} / \mathrm{L}$. Hence, it is feasible to combine ATPS with IC for the enrichment and determination of thiocyanate in raw milk.
\end{abstract}

Keywords: thiocyanate; raw milk; aqueous two-phase system; ion chromatography; extraction

\section{Introduction}

Milk has high nutritional value which is easily digested and absorbed, making it one of the important sources of nutrition for human body, but it is highly prone to spoilage. Thiocyanates are known to be effective in prolonging the shelf life of milk through the lactoperoxidase system (LPS), a naturally occurring enzymatic antimicrobial system in raw milk that promotes the oxidation of halides and thiocyanates by hydrogen peroxide, resulting in a series of antimicrobial compounds [1]. Therefore, in countries where cold chain delivery is underdeveloped, trace amounts of thiocyanate ions are allowed to be added in raw milk to artificially activate LPS for the purpose of temporary inhibition of pathogenic microorganisms. However, thiocyanates are toxic substances that produce $\mathrm{CN}^{-}$ which could bind to $\mathrm{Fe}^{3+}$ in the cytochrome oxidase enzyme in the body, thereby inhibiting the enzyme activity. It would lead to hypoxia in human tissues, even significant damage of kidney function. Lower doses of thiocyanate $(4.8-6.4 \mathrm{mg} / \mathrm{L})$ can competitively inhibit the transport of sodium iodide in the thyroid gland, thereby impairing iodine uptake. Iodide is a key component in the production of thyroid hormones, which plays a critical role in many physiological functions, especially for brain and nervous system development in fetuses and children. The concentration of thiocyanate in plasma above $120 \mathrm{mg} / \mathrm{L}$ usually triggers toxicity, with a lethal concentration of approximately $200 \mathrm{mg} / \mathrm{L}$. In addition, chronic high levels of thiocyanate in physiological fluids could lead to vertigo, nasal bleeding, and 
confusion [2-4]. The International Codex Alimentarius Commission (CAC) allows a limit value of $14 \mathrm{mg} / \mathrm{kg}$ of sodium thiocyanate (in terms of thiocyanate) to be added to raw milk; however, excessive use of thiocyanate is common in practical applications. It was noted that thiocyanate is also a naturally occurring substance in raw milk, and clinical trials by Reiter et al. [5] demonstrated that risky raw milk was related to excess added thiocyanate and that the content of thiocyanate in raw milk needed to be strictly controlled in industrial production. Therefore, the rapid and accurate determination of thiocyanate content in raw milk is of great importance in food safety and health care.

In order to detect thiocyanate, it is necessary to separate and enrich thiocyanate from raw milk, so that the interference of other components of raw milk in the detection process can be excluded. Among the available methods for thiocyanate enrichment, solidphase extraction techniques have mostly been studied. Al-Saidi et al. [6] established a headspace sorptive solid-phase microextraction (HS-SPME) technique for the extraction of thiocyanate and cyanide. Under the optimized conditions, the LOD and LOQ were 0.34 and $1.2 \mathrm{mmol} / \mathrm{L}$, respectively. Da Silva et al. [7] separated thiocyanates using capillary electrophoresis. The ranges of LOD and LOQ were $0.03-0.04$ and $0.05-0.07 \mathrm{mg} / \mathrm{L}$. Although the electromigration technique is inexpensive and environmentally friendly, it requires a high level of professionalism from the operator and is not easily promoted in factories. Lu et al. [8] extracted thiocyanate ions in the aqueous phase with complexes of $\mathrm{Hg}^{2+}$ into methyl isobutyl ketone and the LOD was $1.33 \mathrm{ng} / \mathrm{mL}$. However, the currently reported methods for thiocyanate determination suffer from the disadvantages of cumbersome pretreatment, low sensitivity, many influencing factors, and high cost. Therefore, a more rapid, sensitive, simple, and economical method for the enrichment and detection of thiocyanate in raw milk is necessary.

An aqueous two-phase system (ATPS) is formed mainly by the partitioning of two immiscible solutions. In some fields, ATPS is a novel alternative technique to conventional solvent extraction. ATPS has successfully been used for the extraction and purification of peptides [9], polysaccharides [10], enzymes [11], heavy metals [12], proteins [13], amino acids [14], cells [15], and cytochromes [16], and has also been used for the separation and enrichment of neutral, anionic, and cationic ions [17]. In recent years, some novel, low-cost, and efficient ATPSs have appeared that are different from typical polymer/salt and ionic liquid/salt systems. These ATPSs have received increasing attention due to high extraction efficiency, fast phase separation, low viscosity, mild environmental effects, and recyclability, such as alcohol/inorganic salt systems [18], propanol/inorganic salt systems [19], acetonitrile/inorganic salt systems [20], etc. These ATPSs allow the recovery of small organic molecules from the ATPSs by evaporation and crystallization, making it easy to separate the extract from the rich organic phase, thus reducing the cost of extraction and enrichment, and simplifying the subsequent production process for easy application in downstream production [11]. In analytical applications, such systems easily exclude the possible interference of background in the determination of target substances. Since the introduction of ion chromatography (IC) by Shapiro et al. [21] in 1975, the method has become the preferred method for the determination of small inorganic and organic ions. Thienpont et al. [22] reported that IC could determine the total sodium and potassium concentrations in human serum. Charles et al. [23] proposed a method of ion chromatography-mass spectrometry (IC-MS) to determine bromate ions in water. Fernandes et al. [24] used IC combined with UV detection to detect four bisphosphonates in pharmaceuticals or bulk materials. Now, the determination of thiocyanate in the industry is mostly based on the spectrophotometric method, which is based on the principle that $\mathrm{SCN}^{-}$can generate blood-red iron thiocyanate complex ion ([ $\left.\mathrm{Fe}(\mathrm{SCN}) \mathrm{n}\right]^{\mathrm{m} \pm}$ ) with $\mathrm{Fe}^{3+}$ and $[\mathrm{Fe}(\mathrm{SCN}) \mathrm{n}]^{\mathrm{m} \pm}$ has the maximum absorption peak at $450 \mathrm{~nm}$. The limit of detection mostly approaches $0.05 \mathrm{mg} / \mathrm{L}$. Because of the disadvantages of the spectrophotometric methods such as large interference factors, low sensitivity, and low efficiency, this method is receiving less and less attention. 
The combination of ATPS with ion chromatography (IC) using an anion-exchange column for separation and an amperometric detector or ultraviolet (UV) detector for determination offers the advantages of rapidity and simplicity, and high selectivity and sensitivity. ATPS was applied to the separation and enrichment of thiocyanate in raw milk for the first time in this study. Enrichment of thiocyanate from raw milk using ATPS has the advantages of being rapid, simple, inexpensive, low interference, and environmentally friendly, providing a new pre-treatment method for the determination of thiocyanate. In this study, acetonitrile/ $\left(\mathrm{NH}_{4}\right)_{2} \mathrm{SO}_{4}$ ATPS was compared with acetone/ammonium ATPS for the extraction of thiocyanates from raw milk, and the best extraction system was selected. The extraction conditions were optimized by response surface methodology (RSM) and the extraction mechanism was initially investigated. IC was combined with ATPS for the determination of thiocyanate in raw milk and the feasibility of the method was evaluated using the limit of detection (LOD) and quantification (LOQ), precision, spike recovery, and interference analysis.

\section{Materials and Methods}

\subsection{Materials}

Acetonitrile (ACN) was HPLC grade, KBr was SP grade, and all other reagents were AR grade. Sodium thiocyanate was obtained from Aladdin Industrial Corporation (Shanghai, China). ACN was provided by Dikma Technology Co. Ltd. (Beijing, China). $\mathrm{KBr}$ was purchased from Sinopharm Chemical Reagent Co. Ltd. (Shanghai, China). Other reagents were from Fuchen Chemical Reagents Factory (Tianjin, China).

\subsection{Equipment}

IC analysis was performed on a 930 (Metrohm AG, Herisau, Switzerland) ion chromatography system. Chromatographic separation of sodium thiocyanate was carried out using a Metrosep A Supp5 $(250 \mathrm{~mm} \times 4.0 \mathrm{~mm}, 5 \mu \mathrm{m})$ anion chromatographic column, which utilized $5 \mathrm{mM} \mathrm{Na}_{2} \mathrm{CO}_{3}$ containing $5 \%(v / v)$ acetone as eluent under isocratic conditions at a flowrate of $1.0 \mathrm{~mL} / \mathrm{min}$. The temperature of column and detector was maintained at $35{ }^{\circ} \mathrm{C}$ using a chromatography oven. The suppressor regeneration solution was $\mathrm{H}_{2} \mathrm{SO}_{4}$ solution (10 M). A SC-3610 low speed centrifuge (Zhongke Zhongjia Scientific Instrument Co., Ltd., Hefei, China) and $0.22 \mu \mathrm{m}$ water membrane filters (Jinteng Laboratory Equipment Co., Ltd., Tianjin, China) were used for sample treatment. IR spectra were examined with an ALPHA-T Fourier transform infrared spectrometer (Bruker Daltonics, Karlsruhe, Germany)

\subsection{Pretreatment of Raw Milk}

Raw milk (40 g) was weighed into a colorimetric tube, where $9 \mathrm{~g}$ of trichloroacetic acid aqueous solution $(50 \%, w / w)$ and $1 \mathrm{~g}$ of hydrogen peroxide aqueous solution $(1 \%$, $w / w$ ) were added and mixed. Then, the sample was centrifuged (5000 rmp, $10 \mathrm{~min}$ ), the supernatant was filtered by a $0.22 \mu \mathrm{m}$ water membrane filter [25], and the filtrate was reserved.

\subsection{Preparation of Solution}

The sodium thiocyanate standard was dried in an oven at $80{ }^{\circ} \mathrm{C}$ for $3 \mathrm{~h}$. The dried sodium thiocyanate was accurately weighed to $1.397 \mathrm{~g}$ in a $1000 \mathrm{~mL}$ volumetric flask, fixed to the mark with ultrapure water. Then, the solution was mixed and stored at $4{ }^{\circ} \mathrm{C}$. It was valid for 3 months.

\subsection{Preparation of ATPSs}

Phase systems were prepared by adding predetermined quantities of organic solvent (acetonitrile and acetone), $\left(\mathrm{NH}_{4}\right)_{2} \mathrm{SO}_{4}$, and the filtrate. The $\mathrm{pH}$ of the systems was adjusted with hydrochloric acid or sodium hydroxide. The compositions of ATPS are shown in Table 1. The phase-forming components were mixed using a vortex mixer for $2 \mathrm{~min}$, then 
performed centrifugal separation at $2000 \mathrm{rpm}$ for $3 \mathrm{~min}$. The volume of the top phase of ATPS was recorded. The top phase was collected and concentrated by nitrogen blowing, then the volume of the concentrated solution was recorded and the concentrated solution filtered with the organic filtration $(0.22 \mu \mathrm{m})$. Finally, IC was used to detect the $\mathrm{SCN}^{-}$ content in the concentrated top phase solution. The average of three replicates is reported.

Table 1. The compositions of ATPSs.

\begin{tabular}{|c|c|c|c|c|}
\hline $\begin{array}{c}\text { Organic/( }\left(\mathrm{NH}_{4}\right)_{2} \mathrm{SO}_{4} \\
\text { ATPS }\end{array}$ & Organic Solvent (\%) & $\left(\mathrm{NH}_{4}\right)_{2} \mathrm{SO}_{4}(\%)$ & $\mathrm{pH}$ & Temperature $\left({ }^{\circ} \mathrm{C}\right)$ \\
\hline acetonitrile/ $\left(\mathrm{NH}_{4}\right)_{2} \mathrm{SO}_{4}$ & $\begin{array}{l}30 \\
32 \\
34 \\
36 \\
38 \\
40 \\
42 \\
44 \\
46 \\
\end{array}$ & $\begin{array}{l}10 \\
12 \\
14 \\
16 \\
18 \\
20\end{array}$ & $\begin{array}{l}2.5 \\
3.5 \\
4.5 \\
5.5 \\
7.0\end{array}$ & $\begin{array}{l}25 \\
40 \\
55 \\
70 \\
80\end{array}$ \\
\hline acetone $/\left(\mathrm{NH}_{4}\right)_{2} \mathrm{SO}_{4}$ & $\begin{array}{l}30 \\
32 \\
34 \\
36 \\
38 \\
49\end{array}$ & $\begin{array}{l}10 \\
12 \\
14 \\
16 \\
18 \\
20\end{array}$ & $\begin{array}{l}2 \\
3 \\
4 \\
5 \\
6 \\
7 \\
8\end{array}$ & $\begin{array}{l}25 \\
32 \\
40 \\
50 \\
55\end{array}$ \\
\hline
\end{tabular}

\subsection{Evaluation Index of ATPS}

The separation and enrichment efficiency of $\mathrm{SCN}^{-}$by ATPS were investigated by the recovery rate $(Y)$ and enrichment factor $(C F)$ of $\mathrm{SCN}^{-}$, respectively. The calculation formula was as follows:

$$
\begin{gathered}
Y=\frac{c_{0} \times V \times 1000}{m \times 1000} \times 100 \% \\
C F=\frac{c_{0}}{c_{i}}
\end{gathered}
$$

where $C_{0}$ is the $\mathrm{SCN}^{-}$concentration of the top phase after nitrogen blowing $(\mathrm{mg} / \mathrm{L}) ; V$ is the top phase volume of ATPS after nitrogen blowing $(\mathrm{mL}) ; m$ is the added mass of $\mathrm{SCN}^{-}$ in the system (mg); 1000 is the unit conversion factor; and $C_{i}$ is the concentration of $\mathrm{SCN}^{-}$ before enrichment $(\mathrm{mg} / \mathrm{L})$.

\subsection{RSM Optimization}

Response surface methodology (RSM) was used to analyze the interaction between parallel factors (acetonitrile, ammonium sulfate, $\mathrm{pH}$, and temperature), and Box-Behnken experimental design (BBD) was used to design the experiment. The results are shown in Table 2. Statistical analysis was performed by analysis of variance (ANOVA), the formula listed below was applied to estimate the optimal parameters.

$$
Y=A_{0}+A_{i} \sum x_{i}+A_{i j} \sum x_{i} x_{j}+A_{j} \sum x_{j}^{2}(i \neq j)
$$

where $Y$ is the response; $X_{i}$ and $X_{j}$ are the arguments studied; and $A_{0}, A_{i}, A_{i i}$, and $A_{i j}$ are the constants of nodal increment, linearizing, quadratic, and cross-product terms, respectively. The range of $i$ and $j$ is 1 to 3 . $F$ test was used to evaluate the statistical significance of the model. 
Table 2. Factors and levels of code values in the response surface design.

\begin{tabular}{cccc}
\hline \multirow{2}{*}{ Variables } & \multicolumn{3}{c}{ Coded Variable Levels } \\
\cline { 2 - 4 } & $\mathbf{- 1}^{\mathbf{a}}$ & $\mathbf{0}^{\mathbf{b}}$ & $\mathbf{+ 1}^{\mathbf{c}}$ \\
\hline$x_{1}$ acetonitrile $(w / w) \%$ & 41 & 42 & 43 \\
$x_{2}\left(\mathrm{NH}_{4}\right)_{2} \mathrm{SO}_{4}(w / w) \%$ & 15 & 16 & 17 \\
$x_{3} \mathrm{pH}$ & 3.5 & 4.5 & 5.5 \\
\hline
\end{tabular}

${ }^{\text {a }}$ high level; ${ }^{\mathrm{b}}$ middle level; ${ }^{\mathrm{c}}$ low level.

\subsection{Sample and Result Analysis}

The content of $\mathrm{SCN}^{-}$in the sample $(C)$ was calculated according to the following formula:

$$
C=\frac{\rho V f \times 1000}{m \times 1000}
$$

where $C$ is the concentration of $\mathrm{SCN}^{-}$in the raw milk (mg/kg); $\rho$ is the concentration of $\mathrm{SCN}^{-}$in the top phase of ATPS (mg/L) measured from the standard curve; $V$ is the volume of the top phase of ATPS (mL); $f$ is the dilution factor of the sample solution; $m$ is the sampling mass of the filtrate $(\mathrm{g})$; and 1000 is the unit conversion factor.

The recovery rate of standard addition in the spiked sample $(P)$ is calculated according to the following formula:

$$
P=\frac{c_{2}-c_{1}}{c_{3}} \times 100 \%
$$

where $P$ is the recovery rate in the spiked sample (\%); $C_{1}$ is the concentration of $\mathrm{SCN}^{-}$ in the sample to be tested $(\mathrm{mg} / \mathrm{kg}) ; C_{2}$ is the concentration of the spiked sample to be measured $(\mathrm{mg} / \mathrm{kg})$; and $C_{3}$ is the spiked amount $(\mathrm{mg} / \mathrm{kg})$.

\subsection{Analysis of FTIR}

A measure of $20 \mathrm{mg}$ of powdered potassium bromide $(\mathrm{KBr})$ was ground using a mortar and pestle. The background spectra were recorded using $20 \mathrm{mg}$ of powdered $\mathrm{KBr}$. A suitable amount of the top phase sample was taken and dropped onto a $\mathrm{KBr}$ wafer and the sample was allowed to evaporate before being scanned by FTIR at $4000-400 \mathrm{~cm}^{-1}$.

\subsection{Statistical Analysis}

All experiments were carried out 3 times, and the data are expressed as the mean \pm standard deviation. All data were analyzed by the analysis of variance (ANOVA). Significant differences $(p<0.05)$ between the means were identified by the least significant difference calculations.

\section{Results}

\subsection{Influencing Factors of $\mathrm{SCN}^{-}$Isolation}

\subsubsection{ATPS of Acetonitrile/ $\left(\mathrm{NH}_{4}\right)_{2} \mathrm{SO}_{4}$}

The effects of acetonitrile, ammonium sulfate, $\mathrm{pH}$, and temperature on the separation and enrichment of $\mathrm{SCN}^{-}$were investigated using the recovery $(Y)$ and enrichment factor $(C F)$ as evaluation indicators. As shown in Figure 1A, with increasing mass fraction of acetonitrile, the $Y$ value gradually increased, then stabilized and reached the maximum value at $42 \%(w / w)$, while the $C F$ value continued to decrease. The reason for the increase of $Y$ value was the increase in the mass fraction of acetonitrile, which reduced the water content of the system, increased the electrostatic repulsion of $\mathrm{SO}_{4}{ }^{2-}$ and $\mathrm{SCN}^{-}$, and promoted the retention of $\mathrm{SCN}^{-}$in the top phase. When acetonitrile reached $42 \%(w / w)$, $\mathrm{SCN}^{-}$had been largely enriched in the top phase. 

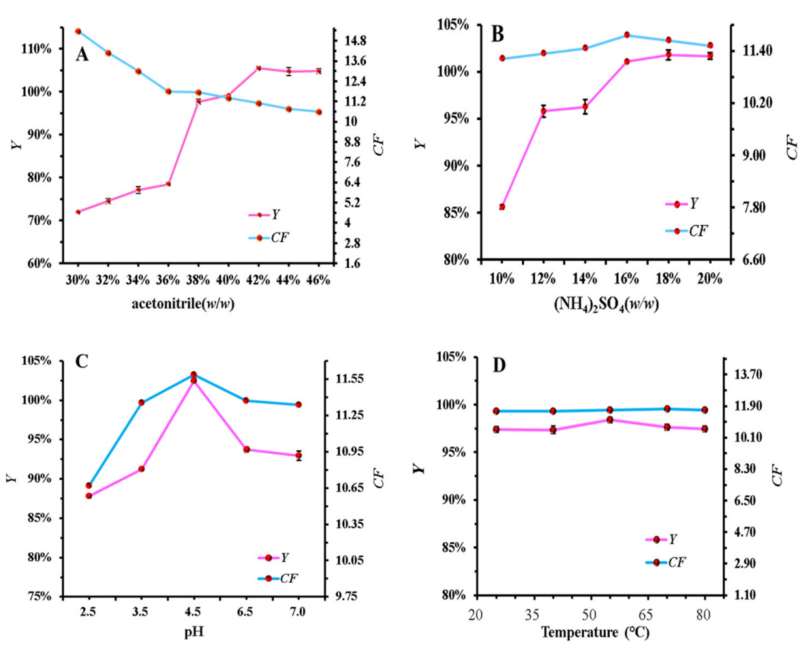

Figure 1. Effect of system composition on $\mathrm{SCN}^{-}$extraction efficiency. (A) acetonitrile (30\%, 32\%, $34 \%, 36 \%, 38 \%, 40 \%, 42 \%, 44 \%$, and $46 \%)$, (B) ammonium sulfate $(10 \%, 12 \%, 14 \%, 16 \%, 18 \%$, and $20 \%),(\mathbf{C}) \mathrm{pH}(2.5,3.5,4.5,5.5$, and 7.0$)$, and (D) temperature $\left(25^{\circ} \mathrm{C}, 40^{\circ} \mathrm{C}, 55^{\circ} \mathrm{C}, 70{ }^{\circ} \mathrm{C}\right.$, and $\left.80{ }^{\circ} \mathrm{C}\right)$.

The effects of inorganic salts on ATPS were as shown in Figure 1B. As the mass fraction of ammonium sulfate increased, the $Y$ value gradually increased and then plateaued and the $C F$ was generally stabilized. The reason for this was that ammonium sulfate was a salt of strong acid and weak base, which could ionize $\mathrm{SO}_{4}{ }^{2-}$ [26]. When the mass fraction of ammonium sulfate reached $16 \%$, the charge repulsion between $\mathrm{SO}_{4}{ }^{2-}$ and $\mathrm{SCN}^{-}$was maximum. However, flocculation was observed in the system when the mass fraction exceeded $20 \%$ and the phase separation interface was not significant. In summary, when the ammonium sulfate mass fraction was $16 \%$, the maximum $Y$ and $C F$ of $\mathrm{SCN}^{-}$in the bottom phase were obtained.

Figure $1 \mathrm{C}$ shows that, as the $\mathrm{pH}$ increased, both $Y$ and $C F$ increased and then decreased, reaching a maximum at $\mathrm{pH}$ 4.5. This is because as the $\mathrm{pH}$ increased, $\mathrm{SO}_{4}{ }^{2-}$ was more favorably assigned to the phase with higher hydrophobicity [27]. When the $\mathrm{pH}$ in the system exceeded 4.5 , the concentration of $\mathrm{H}^{+}$decreased, which resulted in a decrease in the ability of the organic solvent to bind to water [28], and the $\mathrm{SCN}^{-}$reverted to the bottom phase, resulting in a decrease in both $Y$ and $C F$.

With the change of temperature, $Y$ and $C F$ changed less. It indicated that the temperature of the system had no significant effect on the separation and enrichment of $\mathrm{SCN}^{-}$, so the extraction temperature was not further investigated in the subsequent experiments.

In summary, the optimal extraction conditions for the ATPS of acetonitrile and ammonium sulfate were $42 \%(w / w)$ acetonitrile, $16 \%(w / w)$ ammonium sulfate, $\mathrm{pH} 4.5$, and room temperature.

\subsubsection{ATPS of Acetone $/\left(\mathrm{NH}_{4}\right)_{2} \mathrm{SO}_{4}$}

As shown in Figure 2A, with the increase of acetone mass fraction, $Y$ increased and then decreased, and reached the maximum value when the mass fraction of acetone was about $34 \%$, while CF firstly tended to stabilize and then decreased sharply. Because of the hydrophilicity of the organic solvent, some of the water molecules in the bottom phase were competitively adsorbed to the top phase, which made the volume of the bottom phase gradually decrease and the volume of the top phase gradually increase. Moreover, the concentration difference between the top and bottom phase prompted $\mathrm{SCN}^{-}$to enter the top phase with water molecules, so the $Y$ value increased and the $C F$ value stabilized. In addition, the decrease of the volume of the bottom phase led to the increase of the salt concentration in the bottom phase and the salting effect, which prompted the increase of the $Y$ value. Therefore, when the mass fraction of acetone was $34 \%, Y$ and $C F$ values reached maximum. 

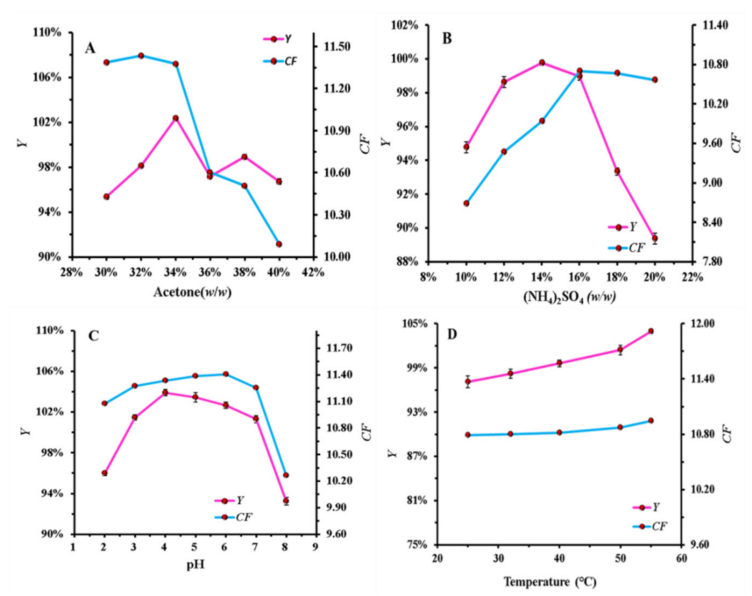

Figure 2. Effect of system composition on $\mathrm{SCN}^{-}$extraction efficiency. (A) acetone (30\%, 32\%, 34\%, $36 \%, 38 \%$, and $40 \%)$, (B) ammonium sulfate $(10 \%, 12 \%, 14 \%, 16 \%, 18 \%$, and $20 \%),(\mathrm{C}) \mathrm{pH}(2,3,4,5,6$, 7 , and 8.0), and (D) temperature $\left(25^{\circ} \mathrm{C}, 32{ }^{\circ} \mathrm{C}, 40{ }^{\circ} \mathrm{C}, 50{ }^{\circ} \mathrm{C}\right.$, and $\left.55^{\circ} \mathrm{C}\right)$.

Figure 2B showed the changes of $C F$ and $Y$ in the mass fraction of ammonium sulfate range of $8-22 \%$. With the increase of the mass fraction of ammonium sulfate, the $Y$ value at first increased and then decreased, reaching the maximum at about $14 \%$, whereas $C F$ continued to increase and stabilized after the mass fraction of ammonium sulfate was $16 \%$. The recoveries of $\mathrm{SCN}^{-}$were $99.77 \pm 0.17 \%$ and $98.96 \pm 0.06 \%$ at $14 \%$ and $16 \%(w / w)$ ammonium sulfate, respectively, with no significant difference, while the enrichment multiple was relatively larger at $16 \%$. Thus, the $16 \%$ mass fraction of ammonium sulfate was chosen as the best condition for the next experiment.

In Figure $2 \mathrm{C}, \mathrm{Y}$ and $\mathrm{CF}$ both increased and later decreased with increasing $\mathrm{pH}$, which was probably due to charge and hydrophobic interactions [29]. While the maximum $Y$ was obtained at around $\mathrm{pH} 4.0, C F$ was maximum at around $\mathrm{pH}$ 6.0, but $C F$ was less variable between $\mathrm{pH} 4.0$ and 6.0. As shown in Figure 2D, the $Y$ value and $C F$ gradually increased with increasing temperature. Since the boiling point of acetone was $56.53^{\circ} \mathrm{C}, 55^{\circ} \mathrm{C}$ was chosen as the best extraction condition. In summary, the optimal extraction conditions for the ATPS of acetone and ammonium sulfate were 34\% (w/w) acetone, $16 \%(w / w)$ ammonium sulfate, $\mathrm{pH} 4.0$, and $55^{\circ} \mathrm{C}$.

\subsection{Comparison of the ATPSs}

Under optimal conditions, the mass fraction of ammonium sulfate was $16 \%$ for both systems and the $\mathrm{pH}$ difference was not significant, while the mass fraction of the organic phase was significantly different. The phase separation ability in the ATPS of organic is related to the polarity of the organic compound, where the greater the polarity, the worse the phase separation ability. Acetonitrile polarity (5.8) is higher than acetone polarity (5.4), which requires more acetonitrile up to the component phase. The results of the single-factor test showed that the $Y$ of the acetonitrile/ammonium sulfate system was $104.23 \pm 0.16 \%$ and the $C F$ was $11.22 \pm 0.02$ under the optimal conditions, and the $Y$ of the acetone/ammonium sulfate system was $103.13 \pm 0.25 \%$ and the $C F$ was $10.38 \pm 0.02$. For both systems, the $Y$ of $\mathrm{SCN}^{-}$were not significantly different, while the CF of the acetonitrile/ammonium sulfate system was larger than that of the acetone/ammonium sulfate system, and the experimental steps were relatively cumbersome because the ATPS of acetone and ammonium needed to be treated with heating. Therefore, RSM was conducted for the ATPS of acetonitrile and ammonium sulfate on the basis of single-factor tests.

\subsection{RSM Optimization of ATPS Conditions}

\subsubsection{Model Fitting and Statistical Analysis}

BBD and RSM were performed to optimize the process parameters for the extraction of $\mathrm{SCN}^{-}$from the ATPS of acetonitrile and ammonium sulfate. The effects of acetonitrile 
mass fraction (15-17\%), ammonium sulfate mass fraction (41-43\%) and system $\mathrm{pH}(3.5-5.5)$ on the $Y$ and $C F$ values of $\mathrm{SCN}^{-}$in the top phase of ATPS were investigated.

The experimental design and results of BBD were shown in Table 3. The regression equation was obtained using Design Expert (Version 8.0.6) software (Statease, Minneapolis, $\mathrm{MN}, \mathrm{USA})$, and the fitted equation was as follows.

$$
\begin{gathered}
C F=10.86+0.060 A+0.14 B+0.32 C+0.045 A B+0.47 A C+0.32 B C-0.34 A^{2}-0.79 B^{2}-1.15 C^{2} \\
Y=106.62+0.90 A+1.09 B+1.94 C-0.11 A B+3.06 A C+2.77 B C-1.82 A^{2}-5.13 B^{2}-9.02 C^{2}
\end{gathered}
$$

where $A, B$, and $C$ are the acetonitrile concentration, $\left(\mathrm{NH}_{4}\right)_{2} \mathrm{SO}_{4}$ concentration, and $\mathrm{pH}$, respectively.

\begin{tabular}{|c|c|c|c|c|c|}
\hline \multirow{2}{*}{ Number } & $A$ & $B$ & $C$ & \multirow{2}{*}{$C F$} & \multirow{2}{*}{$Y(\%)$} \\
\hline & $x_{1}$ Acetonitrile $(w / w) \%$ & $x_{2}\left(\mathrm{NH}_{4}\right)_{2} \mathrm{SO}_{4}(w / w) \%$ & $x_{3} \mathrm{pH}$ & & \\
\hline 1 & 0 & 0 & 0 & 10.98 & 107.13 \\
\hline 2 & -1 & -1 & 0 & 9.30 & 95.20 \\
\hline 3 & 1 & 0 & -1 & 8.46 & 90.22 \\
\hline 4 & 0 & 0 & 0 & 10.74 & 106.42 \\
\hline 5 & -1 & 0 & -1 & 9.54 & 96.70 \\
\hline 6 & 1 & 0 & 1 & 10.14 & 100.99 \\
\hline 7 & 0 & 0 & 0 & 10.56 & 105.64 \\
\hline 8 & 0 & 1 & 1 & 9.48 & 96.59 \\
\hline 9 & 0 & 1 & -1 & 8.34 & 87.93 \\
\hline 10 & 0 & 0 & 0 & 10.56 & 105.07 \\
\hline 11 & 0 & -1 & 1 & 8.88 & 91.47 \\
\hline 12 & 1 & 1 & 0 & 10.26 & 103.92 \\
\hline 13 & 0 & -1 & -1 & 9.00 & 93.91 \\
\hline 14 & -1 & 0 & 1 & 9.36 & 95.22 \\
\hline 15 & 0 & 0 & 0 & 11.46 & 108.83 \\
\hline 16 & -1 & 1 & 0 & 9.78 & 100.20 \\
\hline 17 & 1 & -1 & 0 & 9.60 & 99.37 \\
\hline
\end{tabular}

Table 3. Experimental design and results for BBD.

\subsubsection{Variance Analysis}

The regression model was significant $(p<0.05)$ as seen in Tables 4 and 5, which indicates that the regression equation was ideal. None of the misfit term tests proved to be significant $\left(p_{1}=0.5422>0.05\right.$ and $\left.p_{2}=0.1176>0.05\right)$, suggesting that the model could make good numerical predictions. Combined with Figure 3, the correlation between the predicted and true values of the $C F$ and $Y$ prediction models was relatively good, and coefficients of variation $(C V)$ in this test were $3.71 \%$ and $2.17 \%$, respectively. This demonstrated a high correlation between the predicted and actual values, as well as a high-quality fit.

Table 4. The analysis of variance of the fitting quadratic polynomial prediction model of $C F$.

\begin{tabular}{cccccc}
\hline Source & Sum of Squares & df & Mean Square & $f_{\mathbf{1}}$-Value & $p_{\mathbf{1}}$-Value \\
\hline Model & 11.66 & 9.00 & 0.036 & 9.82 & 0.0033 \\
$\mathrm{~A}$-acetonitrile & 0.029 & 1.00 & 0.0008 & 0.218 & 0.6545 \\
$\mathrm{~B}-\left(\mathrm{NH}_{4}\right)_{2} \mathrm{SO}_{4}$ & 0.15 & 1.00 & 0.0041 & 1.105 & 0.3280 \\
$\mathrm{C}-\mathrm{pH}$ & 0.79 & 1.00 & 0.0221 & 6.018 & 0.0439 \\
Residual & 0.92 & 3.00 & 0.004 & - & - \\
Lack of fit & 0.35 & 4.00 & 0.003 & - & - \\
Pure error & 0.57 & 16.00 & -0.004 & - & - \\
Cor total & 12.58 & - & 3.71 & - & - \\
$C V_{1} \%$ & - & - & 0.93 & - & - \\
$R_{1}{ }^{2}$ & - & & & & - \\
\hline
\end{tabular}


Table 5. The analysis of variance of the fitting quadratic polynomial prediction model of $Y$.

\begin{tabular}{|c|c|c|c|c|c|}
\hline Source & Sum of Squares & df & Mean Square & $f_{2}$-Value & $p_{2}$-Value \\
\hline Model & 617.82 & 9.00 & 68.65 & 14.78 & 0.0009 \\
\hline A-acetonitrile & 6.4441 & 1.00 & 6.4441 & 1.3873 & 0.2774 \\
\hline $\mathrm{B}-\left(\mathrm{NH}_{4}\right)_{2} \mathrm{SO}_{4}$ & 9.4395 & 1.00 & 9.4395 & 2.0321 & 0.1970 \\
\hline $\mathrm{C}-\mathrm{pH}$ & 30.0700 & 1.00 & 30.0700 & 6.4734 & 0.0384 \\
\hline Residual & 32.52 & 7.00 & 4.65 & - & - \\
\hline Lack of fit & 23.97 & 3.00 & 7.99 & 3.74 & 0.1176 \\
\hline Pure error & 8.55 & 4.00 & 2.14 & - & - \\
\hline Cor total & 650.34 & 16.00 & - & - & - \\
\hline$C V_{2} \%$ & - & - & 2.17 & - & - \\
\hline$R_{2}^{2}$ & - & - & 0.95 & - & - \\
\hline
\end{tabular}
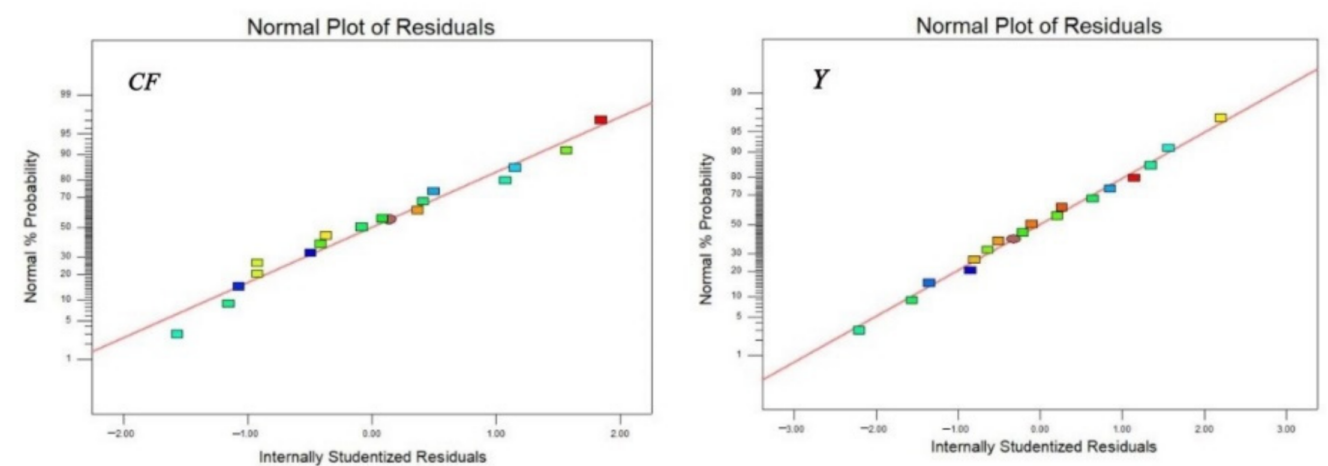

Figure 3. Correlation between predicted value and true value of model CF and $Y$.

\subsubsection{Interactive Analysis}

The response surfaces of the model are shown in Figure 4. The interaction of $\left(\mathrm{NH}_{4}\right)_{2} \mathrm{SO}_{4}$ mass fraction and $\mathrm{pH}$ had the most significant effect on recovery and enrichment multiplicity of $\mathrm{SCN}^{-}$, which is shown in Figure 4e,f. Both a lower mass fraction of $\left(\mathrm{NH}_{4}\right)_{2} \mathrm{SO}_{4}$ and $\mathrm{pH}$ were not favorable for $\mathrm{SCN}^{-}$extraction, however, with increasing mass fraction of $\left(\mathrm{NH}_{4}\right)_{2} \mathrm{SO}_{4}$ and $\mathrm{pH}$, the repulsive force between $\mathrm{SO}_{4}{ }^{2-}$ and $\mathrm{SCN}^{-}$increased, which resulted in $\mathrm{SCN}^{-}$remaining more easily in the top phase. However, as the mass fraction of $\left(\mathrm{NH}_{4}\right)_{2} \mathrm{SO}_{4}$ continued to increase, the system water molecules were reduced and the $\mathrm{pH}$ was increased, which caused the $\mathrm{SCN}^{-}$to retransfer to the bottom phase with the water molecules, resulting in the decrease of the $C F$ and $Y$ of $\mathrm{SCN}^{-}$.

The $3 \mathrm{D}$ response surface plots of the interaction between acetonitrile and $\mathrm{pH}$ on $\mathrm{CF}$ and $Y$ values were shown in Figure $4 \mathrm{c}, \mathrm{d}$. The lower mass fraction of acetonitrile and $\mathrm{pH}$ were not conducive to the transfer of $\mathrm{SCN}^{-}$to the top phase. With the increase of acetonitrile mass fraction, the concentration difference of $\mathrm{SCN}^{-}$in the top and bottom phases was increased, which led to the transfer of $\mathrm{SCN}^{-}$to the top phase. Moreover, with the increase of $\mathrm{pH}$, the protonation of $\mathrm{SO}_{4}{ }^{2-}$ was decreased and the charge repulsion between $\mathrm{SO}_{4}{ }^{2-}$ and $\mathrm{SCN}^{-}$was increased, so $\mathrm{SCN}^{-}$tended to move to the top phase. However, when the acetonitrile content in the system was too high or the $\mathrm{pH}$ was too large, $\mathrm{SCN}^{-}$would re-enter the lower phase, which led to a decrease in both the recovery and the enrichment multiplicity of $\mathrm{SCN}^{-}$[30].

As shown in Figure 4a,b, the interaction between the mass fraction of $\left(\mathrm{NH}_{4}\right)_{2} \mathrm{SO}_{4}$ and the mass fraction of acetonitrile was not significant on the recovery and enrichment multiplicity of $\mathrm{SCN}^{-}$. 
(a)
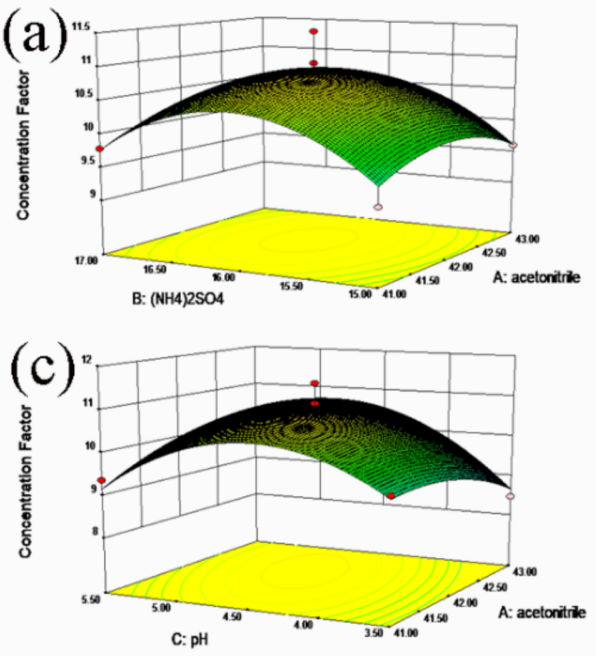

(e)

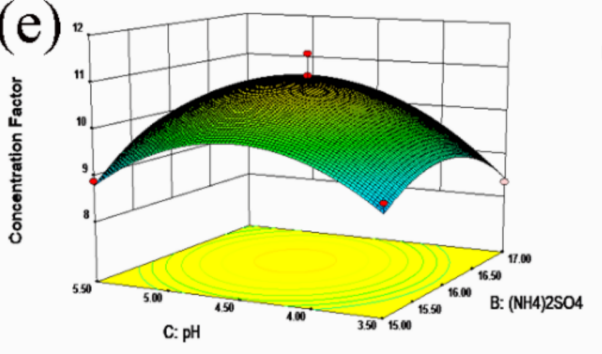

(b)
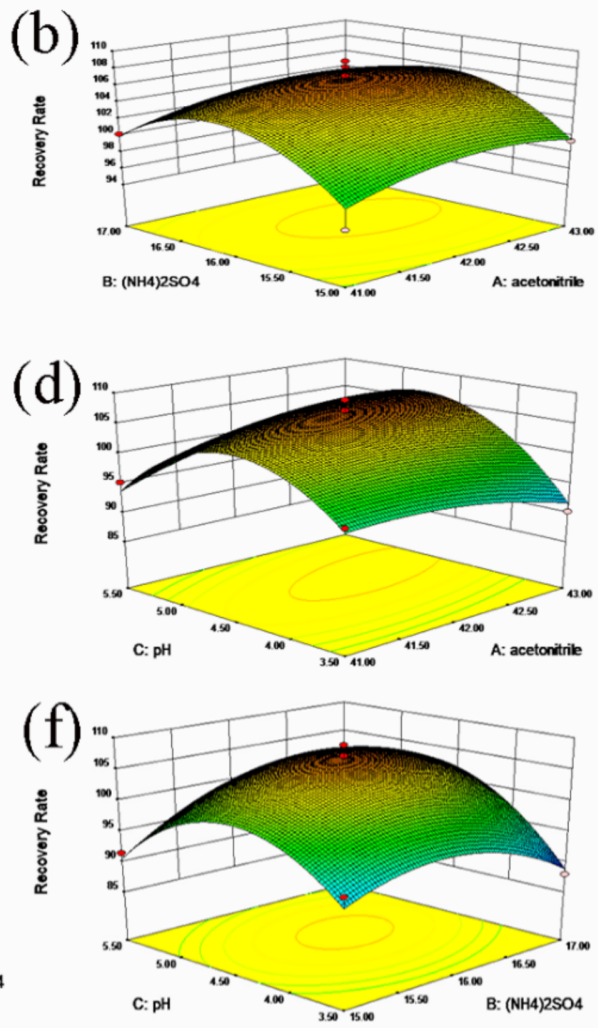

Figure 4. The plots of response surface for $C F(\mathbf{a}, \mathbf{c}, \mathbf{e})$ and $Y(\mathbf{b}, \mathbf{d}, \mathbf{f})$ of $\mathrm{SCN}^{-}$.

\subsubsection{Optimal Conditions and Verification}

After optimization by RSM, its predicted optimal extraction process parameters were composed of room temperature, $42.31 \%$ acetonitrile $(w / w), 16.14 \%\left(\mathrm{NH}_{4}\right)_{2} \mathrm{SO}_{4}(w / w)$, and $\mathrm{pH}$ 4.7. Under these conditions, the predicted values of enrichment multiplicity and recovery of $\mathrm{SCN}^{-}$were 10.92 and $107.06 \%$, respectively. To facilitate the experimental operation, the predicted conditions were rationalized: at room temperature, $42 \%$ acetonitrile $(w / w)$, $16 \%\left(\mathrm{NH}_{4}\right)_{2} \mathrm{SO}_{4}(w / w)$, and $\mathrm{pH}$ 4.7. After experimental verification, the actual enrichment and recovery of the top-phase $\mathrm{SCN}^{-}$were $10.74 \pm 0.03$ and $107.24 \pm 0.5 \%$, respectively, indicating that the optimization results of the response surface experiment were good.

\subsection{Mechanism Analysis}

In this paper, the mechanism of $\mathrm{SCN}^{-}$extraction by ATPS of acetonitrile and $\left(\mathrm{NH}_{4}\right)_{2} \mathrm{SO}_{4}$ was initially explored using FTIR. The comparative IR spectra of the blank ATPS top phase and the ATPS top phase after $\mathrm{SCN}^{-}$enrichment were analyzed separately, and the results are shown in Figure 5. Both top phase solutions showed a characteristic absorption peak of acetonitrile at $2292.45 \mathrm{~cm}^{-1}$ and $2253.89 \mathrm{~cm}^{-1}$, which was produced by the stretching vibration of the $-\mathrm{C} \equiv \mathrm{N}$ group in acetonitrile [31]. The non-occurrence of other new absorption peaks within $4000-500 \mathrm{~cm}^{-1}$ indicated that no new chemical bonds were produced and no weaker interactions between acetonitrile and $\mathrm{SCN}^{-}$were present. The resulting transfer of the $\mathrm{SCN}^{-}$from the bottom to the top phase was caused by the electrostatic repulsion between $\mathrm{SO}_{4}{ }^{2-}$ and $\mathrm{SCN}^{-}$, as well as the effect of the concentration difference, rather than the formation of a new compound between acetonitrile and $\mathrm{SCN}^{-}$. 


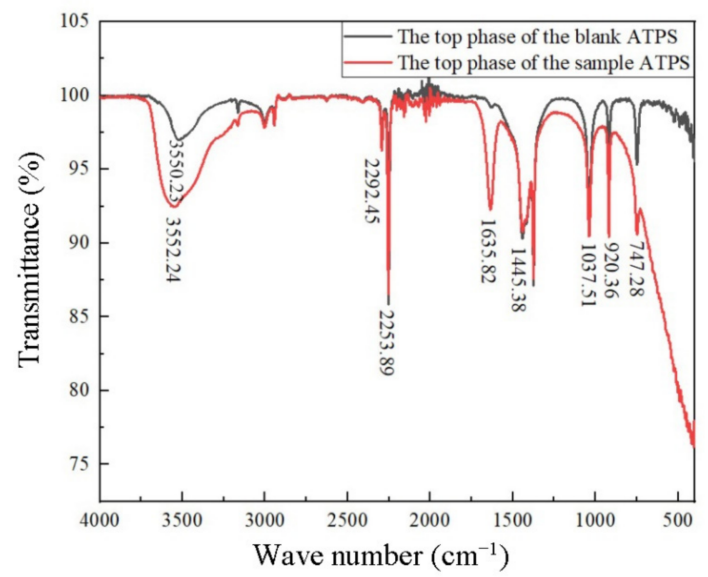

Figure 5. Infrared spectra of acetonitrile/ammonium sulfate ATPS for separation and enrichment of $\mathrm{SCN}^{-}$.

\subsection{Interference Analysis}

The raw milk samples contained many coexisting ions, such as $\mathrm{F}^{-}, \mathrm{Cl}^{-}, \mathrm{NO}_{2}{ }^{-}, \mathrm{NO}_{3}{ }^{-}$, $\mathrm{SO}_{4}{ }^{2-}, \mathrm{PO}_{4}{ }^{3-}$, and other anions. Since the content of $\mathrm{SCN}^{-}$was very low and easily interfered by the coexisting ions, it was necessary to do ion interference experiments. The results in Figure 6 show that the coexisting anions in the sample would not interfere with the determination of $\mathrm{SCN}^{-}$, because the retention capacity of $\mathrm{SCN}^{-}$on the column was much higher than that of $\mathrm{F}^{-}, \mathrm{Cl}^{-}, \mathrm{NO}_{2}{ }^{-}, \mathrm{NO}_{3}{ }^{-}, \mathrm{SO}_{4}{ }^{2-}$, and $\mathrm{PO}_{4}{ }^{3-}$, and the peak time was much later than them.

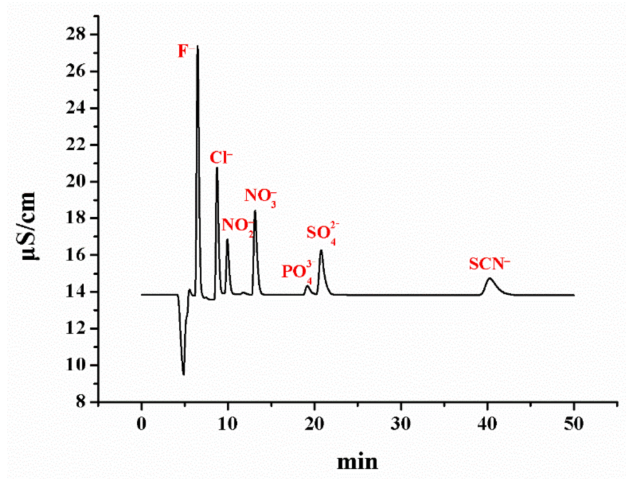

Figure 6. Interference analysis of coexisting ions.

\subsection{Method Validation}

The linearity, precision, and sensitivity of the coupled ATPS-IC technique were validated. All sample determinations were corrected using a blank sample. A representative standard chromatogram is shown in Figure 7. In the range of $0.05-15 \mathrm{mg} / \mathrm{L}$, the concentration of $\mathrm{SCN}^{-}$and the peak area exhibited satisfactory linearity with correlation coefficients $\left(y=223.42 \times-1.39, R^{2}=0.998\right)$. The limit of detection (LOD) and quantification (LOQ) were measured using a series of blank-spiked sample solution. When the peak height of the analytes could be detected to produce a significant response at three-fold and tenfold of the peak height of baseline noise, the concentrations of the analytes were their LODs and LOQs, respectively. LODs and LOQs for SCN ${ }^{-}$were $0.2 \mu \mathrm{g} / \mathrm{L}$ and $0.6 \mu \mathrm{g} / \mathrm{L}$, respectively, and RSDs of intraday and interday were $1.6 \%$ and $4.3 \%$, respectively. 


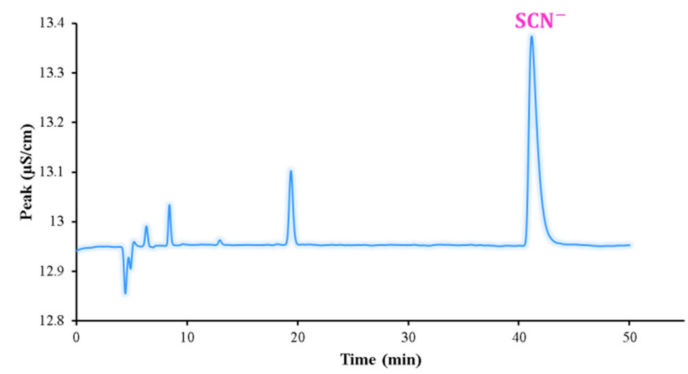

Figure 7. Standard chromatogram of $\mathrm{SCN}^{-}(0.45 \mathrm{mg} / \mathrm{L})$.

\subsection{Application}

The method was applied to determine $\mathrm{SCN}^{-}$contents in raw milk. Analysis was conducted in triplicate. Samples that were spiked with three different concentrations of analytes $(1,5,10 \mathrm{mg} / \mathrm{L})$ were adopted to examine the recovery of the method. Figure 8 shows the representative chromatograms of $\mathrm{SCN}^{-}$. The acetonitrile and $\left(\mathrm{NH}_{4}\right)_{2} \mathrm{SO}_{4}$ extraction system did not interfere with the determination of inorganic anions. The recoveries of the method were in the range of $81-119 \%$ with the relative standard deviations (RSDs) less than $3.7 \%$, indicating that the method was reliable for the determination of $\mathrm{SCN}^{-}$content in raw milk. The recovery results were all presented in Table 6.

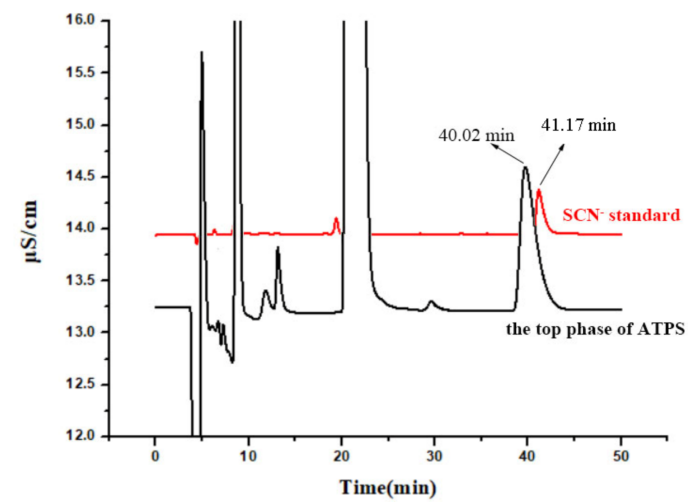

Figure 8. IC chromatograms of $\mathrm{SCN}^{-}$standard $(0.45 \mathrm{mg} / \mathrm{L})$ and the top phase of ATPS.

Table 6. Result of spike recovery experiment.

\begin{tabular}{|c|c|c|c|c|c|c|}
\hline $\begin{array}{l}\text { Addition of } \\
\text { Thiocyanate } \\
\text { (mg/kg) }\end{array}$ & $\begin{array}{c}\text { Found }_{1} \text { b } \\
(\mathrm{mg} / \mathrm{kg})\end{array}$ & $\begin{array}{c}\text { Found }_{2}{ }^{c} \\
(\mathrm{mg} / \mathrm{kg})\end{array}$ & $\begin{array}{c}\text { Found }_{3} \mathrm{~d} \\
(\mathrm{mg} / \mathrm{kg})\end{array}$ & Recovery (\%) & Average (\%) & $\operatorname{RSD}(\%, n=3)$ \\
\hline \multirow{4}{*}{1.00} & & 2.13 & 0.96 & 96 & \multirow{3}{*}{$90 \pm 8$} & \multirow{3}{*}{8.8} \\
\hline & & 1.98 & 0.81 & 81 & & \\
\hline & & 2.10 & 0.93 & 93 & & \\
\hline & 1.17 & 6.84 & 5.67 & 113 & \multirow{3}{*}{$114 \pm 5$} & \multirow{3}{*}{4.5} \\
\hline \multirow[t]{2}{*}{5.00} & & 7.14 & 5.97 & 119 & & \\
\hline & & 6.63 & 5.46 & 109 & & \\
\hline \multirow{3}{*}{10.00} & & 11.65 & 10.48 & 104.8 & \multirow{3}{*}{$108.5 \pm 4.0$} & \multirow{3}{*}{3.7} \\
\hline & & 11.98 & 10.81 & 108.1 & & \\
\hline & & 12.44 & 11.27 & 112.7 & & \\
\hline
\end{tabular}

\footnotetext{
${ }^{\mathrm{b}}$ Corrected by blank sample; ${ }^{\mathrm{c}}$ Corrected by actual sample; ${ }^{\mathrm{d}}$ The value of Found 3 was Found ${ }_{2}$ minus Found . $_{\text {. }}$
}

\subsection{Comparison}

The new method developed in this study was compared with the reported methods for the determination of thiocyanate in raw milk in terms of LOD and RSD, and the results are shown in Table 7 . The LOD of acetonitrile/ $\left(\mathrm{NH}_{4}\right)_{2} \mathrm{SO}_{4}$ ATPS-IC was significantly lower 
compared with the results of IC and HPLC without the extraction pretreatment of ATPS, demonstrating that the pretreatment of the ATPS technique could effectively improve the sensitivity of the thiocyanate detection. In addition, the method developed in this study is simpler, faster, and less costly than other detection methods, enabling highly sensitive and rapid thiocyanate enrichment and detection.

Table 7. Comparison of the present method with other methods for the analysis of thiocyanate.

\begin{tabular}{|c|c|c|c|c|}
\hline Detection Method & Sample & LOD & RSD & Literature \\
\hline acetonitrile/ $\left(\mathrm{NH}_{4}\right)_{2} \mathrm{SO}_{4}$ ATPS-IC & Raw milk & $0.20 \mu \mathrm{g} / \mathrm{L}$ & $1.6 \%$ & This study \\
\hline IC (UV) & Emulsion & $0.08 \mathrm{mg} / \mathrm{L}$ & $0.40 \%$ & [32] \\
\hline Ion Pair Chromatography & Ionic liquid & $0.96 \mathrm{mg} / \mathrm{L}$ & $1.40 \%$ & [33] \\
\hline High Performance Liquid Chromatography (UV) & Emulsion & $0.06 \mathrm{mg} / \mathrm{L}$ & $1.20 \%$ & [34] \\
\hline Colorimetric sensor & Fossil and drill waters & $0.60 \mathrm{mg} / \mathrm{L}$ & $4.50 \%$ & {$[34]$} \\
\hline Gold nanoparticles colorimetry & $\begin{array}{l}\text { Saliva/environmental } \\
\text { water }\end{array}$ & $11.60 \mu \mathrm{g} / \mathrm{L}$ & $3.2 \%$ & [35] \\
\hline $\begin{array}{l}\text { Surface Enhanced Raman Spectroscopy } \\
\text { Methyl }\end{array}$ & Emulsion & $0.04 \mathrm{mg} / \mathrm{L}$ & $<10 \%$ & [36] \\
\hline $\begin{array}{l}\text { Isobutyl Ketone Extraction-Atomic Fluorescence } \\
\text { Spectrometry }\end{array}$ & Seawater & $1.33 \mu \mathrm{g} / \mathrm{L}$ & $2.10 \%$ & [8] \\
\hline Spectrophotometry & Blood & $1.80 \mathrm{mg} / \mathrm{L}$ & $<7 \%$ & [37] \\
\hline Electrode electrochemical method & Saliva & $0.58 \mu \mathrm{g} / \mathrm{L}$ & $2.20 \%$ & [38] \\
\hline
\end{tabular}

\section{Conclusions}

In this study, a highly sensitive and rapid determination of thiocyanate was achieved by using ATPE of acetonitrile/ $\left(\mathrm{NH}_{4}\right)_{2} \mathrm{SO}_{4}$ for the separation and enrichment of thiocyanate, combined with ion chromatography. Optimization of the extraction conditions of the acetonitrile/ $\left(\mathrm{NH}_{4}\right)_{2} \mathrm{SO}_{4}$ system by RSM resulted in a recovery of $107.24 \pm 0.50 \%$ and an enrichment multiple of $10.74 \pm 0.03$ for thiocyanate. The extraction mechanism was initially explored by FTIR. The constructed acetonitrile/ $\left(\mathrm{NH}_{4}\right)_{2} \mathrm{SO}_{4}$ ATPS-IC method showed the linear range of the method was from $0.05 \mathrm{mg} / \mathrm{L}$ to $15 \mathrm{mg} / \mathrm{L}$, and $\mathrm{R}^{2}=0.998$, the LOD was $0.2 \mu \mathrm{g} / \mathrm{L}$, the LQD was $0.6 \mu \mathrm{g} / \mathrm{L}$, the intraday precision was $1.6 \%$, the interday precision was $4.3 \%$, and the recovery rates of standard addition were between $81 \%$ and $119 \%$.

Author Contributions: Data curation, S.Z., H.Y., and P.C.; formal analysis, S.Z., P.C. and B.L.; funding acquisition, B.J., Z.F. and B.T.; investigation, S.Z. and H.Y.; methodology, B.J., D.L., C.L., Z.F. and B.T.; project administration, B.J., Z.F. and B.T.; writing-original draft, B.J., S.Z. and H.Y.; writing-review and editing, B.J., Z.F. and B.T. All authors have read and agreed to the published version of the manuscript.

Funding: This research was funded National Key Research and Development Program of China (2018YFC1604204).

Conflicts of Interest: The authors declare that they have no known competing financial interest or personal relationships that could have appeared to influence the work reported in this paper.

\section{References}

1. Fweja, L.W.; Lewis, M.J.; Grandison, A.S. Alternative strategies for activation of the natural lactoperoxidase system in cows' milk: Trials in Tanzania. J. Dairy Res. 2007, 74, 381-386. [CrossRef]

2. Braverman, L.E.; He, X.; Pino, S.; Cross, M.; Magnani, B.; Lamm, S.H.; Kruse, M.B.; Engel, A.; Crump, K.S.; Gibbs, J.P. The effect of perchlorate, thiocyanate, and nitrate on thyroid function in workers exposed to perchlorate long-term. J. Clin. Endocrinol. Metab. 2005, 90, 700-706. [CrossRef] [PubMed]

3. Pena-Pereira, F.; Lavilla, I.; Bendicho, C. Paper-based analytical device for instrumental-free detection of thiocyanate in saliva as a biomarker of tobacco smoke exposure. Talanta 2016, 147, 390-396. [CrossRef] [PubMed]

4. Yu, P.; Deng, M.; Yang, Y.; Nie, B.; Zhao, S. 3D Microfluidic Devices in a Single Piece of Paper for the Simultaneous Determination of Nitrite and Thiocyanate. Sensors 2020, 20, 4118. [CrossRef] [PubMed]

5. Meuwissen, H.; Rodey, G.; McArthur, J.; Pabst, H.; Gatti, R.; Chilgren, R.; Hong, R.; Frommel, D.; Coifman, R.; Good, R. Bone marrow transplantation: Therapeutic usefulness and complications. Am. J. Med. 1971, 51, 513-532. [CrossRef] 
6. Al-Saidi, H.M.; Al-Harbi, S.A.; Aljuhani, E.H.; El-Shahawi, M.S. Headspace sorptive solid phase microextraction (HS-SPME) combined with a spectrophotometry system: A simple glass devise for extraction and simultaneous determination of cyanide and thiocyanate in environmental and biological samples. Talanta 2016, 159, 137-142. [CrossRef]

7. da Silva, M.; Fernandes Sako, A.V.; Micke, G.A.; Vitali, L. A rapid method for simultaneous determination of nitrate, nitrite and thiocyanate in milk by CZE-UV using quaternary ammonium chitosan as electroosmotic flow inverter. J. Food Compos. Anal. 2020, 88, 103455. [CrossRef]

8. Lu, J.; Bu, J.; Ni, H.; Huang, Y. Indirect Determination of Thiocyanate Ions in Seawater by Methyl Isobutyl Ketone ExtractionAtomic Fluorescence Spectrometry. Asian J. Chem. 2014, 26, 3917-3919. [CrossRef]

9. Oppermann, S.; Oppermann, C.; Bohm, M.; Kuhl, T.; Imhof, D.; Kragl, U. Quantification of amino acids and peptides in an ionic liquid based aqueous two-phase system by LC-MS analysis. AMB Express 2018, 8, 66. [CrossRef]

10. Jiang, B.; Wang, L.; Zhu, M.; Wu, S.; Wang, X.; Li, D.; Liu, C.; Feng, Z.; Tian, B. Separation, structural characteristics and biological activity of lactic acid bacteria exopolysaccharides separated by aqueous two-phase system. LWT 2021, 147, 111617. [CrossRef]

11. Jiang, B.; Wang, M.; Wang, X.; Wu, S.; Li, D.; Liu, C.; Feng, Z.; Li, J. Effective separation of prolyl endopeptidase from Aspergillus Niger by aqueous two phase system and its characterization and application. Int. J. Biol. Macromol. 2021, 169, $384-395$. [CrossRef] [PubMed]

12. Bettio, B.G.; Okumura, L.L.; Zacché, D.S.; Chagas, F.O.; Hespanhol, M.C. Square-wave Anodic Stripping Voltammetric Method for Novelty Detection of Bismuth Extracted by Aqueous Two-phase Systems. Electroanalysis 2021, 33, 1081-1087. [CrossRef]

13. Jiang, B.; Wang, L.; Wang, M.; Wu, S.; Wang, X.; Li, D.; Liu, C.; Feng, Z.; Chi, Y. Direct separation and purification of alphalactalbumin from cow milk whey by aqueous two-phase flotation of thermo-sensitive polymer/phosphate. J. Sci. Food Agric. 2021, 101, 4173-4182. [CrossRef] [PubMed]

14. Mokshina, N.Y.; Shkinev, V.M.; Shatalov, G.V.; Pakhomova, O.A.; Spivakov, B.Y. Extraction Systems Based on N-Vinylformamide for the Extraction and Separation of Cyclic Amino Acids. Dokl. Chem. 2020, 493, 113-116. [CrossRef]

15. Shin, H.; Han, C.; Labuz, J.M.; Kim, J.; Kim, J.; Cho, S.; Gho, Y.S.; Takayama, S.; Park, J. High-yield isolation of extracellular vesicles using aqueous two-phase system. Sci. Rep. 2015, 5, 13103. [CrossRef] [PubMed]

16. Caldeira, A.C.R.; Franca, W.F.L.d.; Converti, A.; Lima, W.J.N.; Sampaio, F.C.; Faria, J.T.d. Liquid-liquid equilibria in aqueous two-phase ethanol/salt systems at different temperatures and their application to anthocyanins extraction. Food Sci. Technol. 2019, 39, 711-717. [CrossRef]

17. Assis, R.C.; Mageste, A.B.; de Lemos, L.R.; Orlando, R.M.; Rodrigues, G.D. Application of aqueous two-phase system for selective extraction and clean-up of emerging contaminants from aqueous matrices. Talanta 2021, 223, 121697. [CrossRef] [PubMed]

18. de Barros, D.P.; Campos, S.R.; Madeira, P.P.; Azevedo, A.M.; Baptista, A.M.; Aires-Barros, M.R. Modeling the partitioning of amino acids in aqueous two phase systems. J. Chromatogr. A 2014, 1329, 52-60. [CrossRef]

19. Wu, Z.-M.; Hao, C.-L.; Tong, T.; Zheng, R.-C.; Zheng, Y.-G. Purification of (S)-3-cyano-5-methylhexanoic acid from bioconversion broth using an acetone/ammonium sulfate aqueous two-phase system. Process Biochem. 2020, 89, 186-192. [CrossRef]

20. Sankaran, R.; Show, P.L.; Yap, Y.J.; Lam, H.L.; Ling, T.C.; Pan, G.-T.; Yang, T.C.K. Sustainable approach in recycling of phase components of large scale aqueous two-phase flotation for lipase recovery. J. Clean. Prod. 2018, 184, 938-948. [CrossRef]

21. Small, H.; Stevens, T.S.; Baumann, W.C. Novel ion exchange chromatographic method using conductimetric detection. Anal. Chem. 1975, 47, 1801-1809. [CrossRef]

22. Thienpont, L.M.; Nuwenborg, J.; Chemistry, D.S.J.A. Ion chromatography as potential reference methodology for the determination of total sodium and potassium in human serum. J. Chromatogr. A 1995, 706, 443-450. [CrossRef]

23. Charles, L.; Pepin, D.; Casetta, B.J.A.C. Electrospray Ion Chromatography-Tandem Mass Spectrometry of Bromate at Sub-ppb Levels in Water. Anal. Chem. 1996, 68, 2554-2558. [CrossRef] [PubMed]

24. Fernandes, C.; Leite, R.S.; Lancas, F.M. Rapid determination of bisphosphonates by ion chromatography with indirect UV detection. J. Chromatogr. Sci. 2007, 45, 236-241. [CrossRef] [PubMed]

25. Jiao, Q.; Liu, Z.; Li, B.; Tian, B.; Zhang, N.; Liu, C.; Feng, Z.; Jiang, B. Development of Antioxidant and Stable Conjugated Linoleic Acid Pickering Emulsion with Protein Nanofibers by Microwave-Assisted Self-Assembly. Foods 2021, 10, 1892. [CrossRef]

26. Kwon, Y.J.; Kaul, R.; Mattiasson, B. Extractive lactic acid fermentation in poly (ethyleneimine)-based aqueous two-phase system. Biotechnol. Bioeng. 1996, 50, 280-290. [CrossRef]

27. Oliveranappa, A.; Lagomarsino, G.; Andrews, B.; Asenjo, J. Effect of electrostatic energy on partitioning of proteins in aqueous two-phase systems. J. Chromatogr. B 2004, 807, 81-86. [CrossRef] [PubMed]

28. Jiang, B.; Na, J.; Wang, L.; Li, D.; Liu, C.; Feng, Z. Reutilization of food waste: One-step extration, purification and characterization of ovalbumin from salted egg white by aqueous two-phase flotation. Foods 2019, 8, 286. [CrossRef] [PubMed]

29. Da, S.M.; Arruda, M.A.J.T. An aqueous two-phase system as a strategy for serum albumin depletion. Talanta 2009, 77, 985-990. [CrossRef]

30. Wang, Q.; Liu, W.; Tian, B.; Li, D.; Liu, C.; Jiang, B.; Feng, Z. Preparation and Characterization of Coating Based on Protein Nanofibers and Polyphenol and Application for Salted Duck Egg Yolks. Foods 2020, 9, 449. [CrossRef]

31. Zhang, Y.; Liang, S.; Zhang, J.; Chi, Y.; Tian, B.; Li, L.; Jiang, B.; Li, D.; Feng, Z.; Liu, C. Preparation of whey protein isolate nanofibrils by microwave heating and its application as carriers of lipophilic bioactive substances. Lwt 2020, 125, 109213. [CrossRef]

32. Qiaoyan, Y.; Yanan, G.; Mei, L.; Fang, W.; Nan, Z.; Jiaqi, W. Determination of Thiocyanate in Raw Milk by Ion Chromatography. China Dairy Cattle 2020, 4, 49-54. [CrossRef] 
33. Ma, Y.-J.; Li, M.; Yu, H.; Li, R.-S. Fast analysis of thiocyanate by ion-pair chromatography with direct conductivity detection on a monolithic column. Chin. Chem. Lett. 2013, 24, 1067-1069. [CrossRef]

34. Gavrilenko, N.A.; Volgina, T.N.; Gavrilenko, M.A. Colorimetric sensor for determination of thiocyanate in fossil and drill waters. Mendeleev Commun. 2017, 27, 529-530. [CrossRef]

35. Zhang, Z.; Zhang, J.; Qu, C.; Pan, D.; Chen, Z.; Chen, L. Label free colorimetric sensing of thiocyanate based on inducing aggregation of Tween 20-stabilized gold nanoparticles. Analyst 2012, 137, 2682-2686. [CrossRef] [PubMed]

36. Feng, Y.; Mo, R.; Wang, L.; Zhou, C.; Hong, P.; Li, C. Surface Enhanced Raman Spectroscopy Detection of Sodium Thiocyanate in Milk Based on the Aggregation of Ag Nanoparticles. Sensors 2019, 19, 1363. [CrossRef] [PubMed]

37. Zot, P.; Gin, G.; Bachmann, L. Validation of a Thiocyanate Method on the Shimadzu UV-1800 Spectrophotometer. Am. J. Clin. Pathol. 2019, 152, S83-S84. [CrossRef]

38. Easow, J.S.; Gnanaprakasam, P.; Selvaraju, T. Synergistic effect of bimetallic Ag@Cu nanorods modified electrode for enhanced electrochemical sensing of thiocyanate ions. Res. Chem. Intermed. 2015, 42, 2539-2551. [CrossRef] 